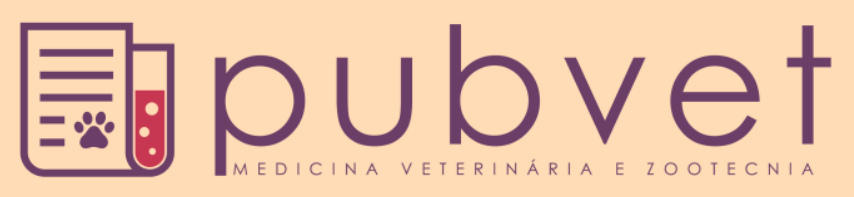

https://doi.org/10.31533/pubvet.v12n9a171.1-6

\title{
Composição química da silagem de milho com aditivos
}

\author{
Raquelline Rodrigues Figueiredo ${ }^{1^{*}}$, Ana Paula Silveira Souza Freire ${ }^{2}$, André Madeira \\ Silveira França $^{30}$, Isabel Cristina Ferreira ${ }^{4}$, Ednaldo Carvalho Guimarães ${ }^{50}$ \\ ${ }^{I}$ Médica Veterinária pela Universidade Federal de Uberlândia, Faculdade de Medicina Veterinária. Uberlândia-MG. Brasil. \\ ${ }^{2}$ Médica Veterinária pela Universidade Federal de Uberlândia, Faculdade de Medicina Veterinária. Uberlândia-MG. Brasil. \\ ${ }^{3}$ Mestre em Ciências Veterinárias pela Universidade Federal de Uberlândia, Faculdade de Medicina Veterinária. Uberlândia-MG. Brasil. \\ ${ }^{4}$ Pesquisador da Empresa Brasileira de Pesquisa Agropecuária (Brasília-DF, Brasil). E-mail: Isabel.ferreira@embrapa.br \\ ${ }^{5}$ Professor Titular da Universidade Federal de Uberlândia, Faculdade de Matemática. Uberlândia-MG. Brasil. E-mail: ecg@ufu.br \\ *Autor para correspondência. E-mail: llinevet@gmail.com
}

RESUMO. A silagem de milho é um dos alimentos conservados mais utilizados na produção animal durante a seca. Objetivou-se avaliar a composição química da silagem de milho com diferentes aditivos. O delineamento foi casualizado, em esquema fatorial $3 \times 3$ (três valores de adição do coproduto farelo úmido de glúten de milho e dois aditivos + um sem aditivo), com três repetições, totalizando 27 unidades experimentais. Foi utilizada análise de variância com 5\% de significância e teste de Scott-Knott para os dados obtidos. Os valores de nutrientes digestíveis totais e de matéria seca aumentaram proporcionalmente às inclusões do coproduto nas silagens com aditivos. As variáveis proteína bruta e fibra em detergente neutro apresentaram o mesmo comportamento, enquanto os valores de fibra em detergente ácido sofreram redução nas silagens com $30 \%$ do coproduto. Silagens tratadas com benzoato apresentaram maiores teores de cinzas. Menores valores para o teor de extrato etéreo foram encontrados nas silagens sem inclusão do coproduto. O uso de 15 e $30 \%$ de farelo úmido de glúten de milho não teve efeito sobre a composição química da silagem.

Palavras-chave: coproduto, farelo úmido de glúten de milho, produção animal

\section{Chemical composition of corn silage with additives}

\begin{abstract}
Corn silage is one of the most conserved feed used in animal production during drought. The objective of this study was to evaluate the chemical composition of corn silage with different additives. The design was randomized, in a 3x3 factorial scheme (three values of the addition of wet corn gluten feed and two additives + one without additive), with three replications, totaling 27 experimental units. We used analysis of variance with 5\% significance and Scott-Knott's test for the data obtained. The values of total digestible nutrients and dry matter increased proportionally to the co-product inclusions in the silages with additives. The crude protein and neutral detergent fiber presented the same behavior, while the values of acid detergent fiber were reduced in the silages with $30 \%$ of the co-product. Silages treated with benzoate showed higher ash content. Lower values for ethereal extract content were found in the silages without inclusion of the co-product. The use of 15 and $30 \%$ of wet corn gluten feed had no effect on the chemical composition of the silage.
\end{abstract}

Keywords: co-product, wet corn gluten feed, animal production

\section{Composición química del ensilaje de maíz con aditivos}

RESUMEN. El ensilaje de maíz es uno de los alimentos conservados más utilizados en la producción animal durante la sequía. El objetivo de este estudio fue evaluar la composición 
química del ensilaje de maíz con diferentes aditivos. El diseño fue aleatorizado, en un esquema factorial $3 \times 3$ (tres valores de la adición de alimento de gluten de maíz húmedo y dos aditivos + uno sin aditivo), con tres repeticiones, totalizando 27 unidades experimentales. Fue utilizado el análisis de varianza con una significación del $5 \%$ y la prueba de Scott-Knott para los datos obtenidos. Los valores de nutrientes digestibles totales y materia seca aumentaron proporcionalmente a las inclusiones de coproductos en los ensilajes con aditivos. La proteína cruda y la fibra en detergente neutro presentaron el mismo comportamiento, mientras que los valores de fibra en detergente ácido se redujeron en los ensilajes con un 30\% del coproducto. Los ensilajes tratados con benzoato mostraron un mayor contenido de cenizas. Los valores más bajos para el contenido de extracto etéreo se encontraron en los ensilajes sin inclusión del coproducto. El uso de 15 y $30 \%$ de salvado húmedo de gluten de maíz no tuvo ningún efecto sobre la composición química del ensilaje.

Palabras clave: coproducto, salvado húmedo de gluten de maíz, producción animal

\section{Introdução}

A principal forma de criação de ruminantes encontrada no Brasil é a pasto (Moreira et al., 2015). As pastagens, no entanto, apresentam estacionalidade produtiva, devido às variações climáticas ocorrentes entre as estações.

Algumas alternativas são utilizadas pelos produtores para contornar a dificuldade da produção uniforme do pasto ao longo do ano, sendo a ensilagem uma das formas mais comuns de conservação de forragem empregadas na alimentação animal (Santos et al., 2017). É utilizada principalmente para conservar alimentos com teor de umidade elevado.

A planta do milho é uma das forrageiras mais utilizadas para a produção de silagem, devido ao seu potencial nutricional e perfil de fermentação desejável (Júnior et al., 2017). Além disso, pode ser aditivada com inoculantes bacterianos ou conservantes para alimentos, que permitirão aumento ou manutenção do seu valor nutricional e qualidade após a abertura do silo (Moraes et al., 2017).

Simultaneamente às estratégias de armazenamento de alimentos na nutrição animal para a época da seca, pode-se também utilizar a suplementação da alimentação com coprodutos industriais, como por exemplo, o farelo de glúten de milho (França et al., 2015). Essa utilização é também uma opção para a redução do impacto ambiental da pecuária extensiva, além de consistir em uma fonte nutricional de qualidade e ser viável economicamente.

Objetivou-se avaliar a composição química da silagem de milho incluída de farelo úmido de glúten de milho (FUGM) associado a $0,1 \%$ de benzoato de sódio e ao inoculante bacteriano contendo Lactobacillus plantarum e
Propionibacterium acidipropionici. Tendo em vista a pouca informação na literatura sobre o FUGM incluído às silagens com e sem aditivos o experimento pode colaborar com o banco de dados sobre silagens de plantas forrageiras com coprodutos e inoculantes, auxiliando o produtor a avaliar as melhores interações e permitindo a tomada de decisão.

\section{Material e métodos}

$\mathrm{O}$ experimento foi executado na cidade de Uberlândia, região do Triângulo Mineiro, Minas Gerais. A silagem foi produzida no setor de caprino e ovinocultura da Fazenda Experimental Capim Branco da Universidade Federal de Uberlândia. As análises laboratoriais, por sua vez, foram executadas no Laboratório de Análise de Matérias Primas e Rações (LAMRA) da Faculdade de Medicina Veterinária da Universidade Federal de Uberlândia.

Foi realizado delineamento inteiramente casualizado, em esquema fatorial $3 \times 3$ (três níveis de inclusão de FUGM e dois aditivos + um sem aditivo), com três repetições e dois dias de coletas (ao dia zero e após 56 dias de ensilagem). Foram confeccionados 27 "minisilos" experimentais de tubos de policloreto de vinil (PVC) silagem de milho incluída de 0,15 e $30 \%$ de farelo úmido de glúten de milho na matéria natural e dois tipos de aditivos: benzoato de sódio a $0,1 \%$ na base natural e inoculante bacteriano contendo Lactobacillus plantarum e Propionibacterium acidipropionici.

Nos tratamentos aditivados com benzoato de sódio a $0,1 \%$ foram adicionados um quilo do conservante homogeneizado manualmente ao volume total. Nos aditivados com inoculante bacteriano foram aplicadas $10^{4}$ unidades formadores de colônias (UFC) de Lactobacillus plantarum e $10^{4}$ UFC de Propionibacterium 
acidipropionici por grama de FUGM. As concentrações dos microrganismos, bem como a aspersão do produto atenderam às normas do fabricante. O farelo úmido de glúten de milho empregado tem como referência a composição química observada por França et al. (2015), conforme a tabela a seguir (Tabela 1).

Tabela 1. Composição química e teor de nutrientes digestíveis totais (NDT) do farelo úmido de glúten de milho.

\begin{tabular}{lc}
\hline Itens, \% & França et al. (2015) \\
\hline Matéria seca & 47,54 \\
Cinzas & 7,64 \\
Proteína bruta & 25,90 \\
FDN $^{1}$ & 48,95 \\
FDA $^{2}$ & 13,44 \\
EE $^{3}$ & 0,96 \\
NDT $^{4}$ & 77,99 \\
\hline
\end{tabular}

${ }^{1} \mathrm{FDN}=$ fibra em detergente neutro; ${ }^{2} \mathrm{FDA}=$ fibra em detergente ácido; ${ }^{3} \mathrm{EE}=$ extrato etéreo e ${ }^{4} \mathrm{NDT}=$ nutrientes digestíveis totais. Fonte: Adaptado de França et al. (2015).

Inseriu-se aproximadamente 600 gramas de areia previamente tratada no interior de cada silo para drenagem do líquido de lixiviação produzido durante a ensilagem. Esta foi separada da silagem por meio de uma tela de material plástico e permeável. A silagem foi homogeneizada manualmente e compactada com as mãos, buscando-se atingir a densidade de $550 \mathrm{~kg} / \mathrm{m}^{3}$. A parte superior de cada unidade experimental foi coberta e vedada por uma tampa plástica em policloreto de vinila (PVC) com bico tipo Bunsen na extremidade, para a saída dos gases resultantes da fermentação. Os componentes utilizados na confecção dos silos, incluindo os próprios tubos e o material ensilado, tiveram seu peso obtido por balança em mesa, com variação de um grama. Após vedados com fita adesiva os "minisilos" foram acondicionados em local coberto, seco e arejado.

Nos dias zero e 56 após a ensilagem, foram coletadas aproximadamente $400 \mathrm{~g}$ de amostras de cada tubo, devidamente homogeneizadas e armazenadas em sacos plásticos identificados e enviadas imediatamente para posterior análise em laboratório. As análises da composição química foram realizadas antes e depois do processo de ensilagem, consistindo inicialmente na pesagem em balança digital de precisão e posterior secagem em estufa em condição de circulação forçada de ar a $55^{\circ} \mathrm{C}$ por 72 horas para o resultado parcial do teor de MS. Depois disso as amostras foram moídas em moinho de facas com crivo $1 \mathrm{~mm}$ nas peneiras e submetidas ao analisador de umidade por infravermelho. Em seguida foram realizados procedimentos para determinação de fibra em detergente neutro (FDN), fibra em detergente ácido (FDA), matéria mineral (MM), extrato etéreo (EE) e proteína bruta (PB - pelo método de Kjeldahl), segundo Silva \& Queiroz (2006).

Na comparação das médias foi utilizado o teste de Scott-Knott que define grupos homogêneos de médias. Para análise de variância e o teste de Scott-Knott (com 5\% de significância) foi utilizado o software SISVAR (Ferreira, 2011).

\section{Resultados e discussão}

O valor nutricional da silagem obtida foi similar ao esperado para silagens de milho em geral. Os teores da composição química da planta para produção da silagem de milho no instante da ensilagem com e sem os aditivos estão representados na Tabela 2.

Segundo Marafon et al. (2015), o valor nutricional da silagem é um dos fatores mais importantes para determinar a sua qualidade. Com relação à matéria seca observa-se que não se encontrou diferença $(\mathrm{P}>0,05)$ entre as silagens tratadas com 0 e $15 \%$ de adição do coproduto. No caso das silagens com $30 \%$ do coproduto houve diferença $(\mathrm{P}<0,05)$ entre o grupo sem aditivos e os demais, sendo que as que receberam benzoato e o inoculante apresentaram maiores teores de MS.

Santos et al. (2012) caracterizaram silagens de milho com diferentes valores de adição de farelo úmido de glúten de milho (0, 30 e 60 e $90 \%)$ e concluíram que o teor de MS das silagens sofre aumento diretamente proporcional aos níveis de inclusão do coproduto, conforme ocorreu neste experimento. Tal comportamento se dá pela quantidade de matéria seca do produto ensilado, que quanto maior, mais favorece a conservação do alimento por inibir o desenvolvimento de microrganismos considerados prejudiciais à qualidade do alimento e indesejáveis.

Na silagem com 30\% de FUGM e nenhum aditivo, houve perdas numéricas no teor de MS em 1,29\% durante os 56 dias de armazenamento. As silagens tratadas com benzoato com 0 e $30 \%$ de adição do coproduto e as tratadas com inoculante com $15 \%$ de inclusão também sofreram perdas numéricas durante os 56 dias de fermentação de 3,$45 ; 0,03$ e $1,21 \%$, respectivamente.

Para o teor de cinzas não houve diferença $(\mathrm{P}>0,05)$ entre as silagens tratadas com 0 e $30 \%$ de inclusão de FUGM. No entanto, com relação à 
silagem com $15 \%$ de inclusão observou-se diferença $(\mathrm{P}<0,05)$ em todos os tratamentos, sendo o maior valor encontrado na que foi tratada com benzoato. Nas silagens aditivadas com inoculante não se encontrou diferença entre os níveis de adição (P>0,05) (Tabela 3).

Não houve diferença $(\mathrm{P}>0,05)$ em relação à $\mathrm{PB}$ entre os tratamentos para as silagens com inclusão de 0 e $30 \%$ de FUGM acrescidas ou não com aditivos. Na silagem com $15 \%$ de inclusão do coproduto houve diferença $(\mathrm{P}<0,05)$ entre todos os tratamentos, sendo que o maior teor foi obtido com o benzoato de sódio a $0,1 \%$.

A silagem sem FUGM acrescida de benzoato apresentou $(\mathrm{P}<0,05)$ menor teor de $\mathrm{PB}$ em relação às silagens com 15 e $30 \%$ de FUGM. Já para as silagens com inoculante bacteriano resultaram em maior $(\mathrm{P}<0,05)$ teor de $\mathrm{PB}$ para o nível de inclusão de $30 \%$ do coproduto. A presença do inoculante bacteriano e do provavelmente permitiu teores elevados do nutriente ao inibir a proliferação de uma microflora que impediu a alta degradação proteica. De modo geral, semelhantemente ao que ocorreu no teor de matéria seca, a quantidade de proteína bruta aumentou paralelamente ao nível de inclusão do coproduto, provavelmente devido ao elevado teor desse nutriente presente no FUGM.

Segundo Assad et al. (2015), o teor proteico na fermentação microbiana efetiva no rúmen requer uma quantidade mínima de $7 \%$ de proteína bruta no alimento. A silagem de milho incluída de diferentes níveis de FUGM e aditivos possui teores de $\mathrm{PB}$ adequados aos exigidos pelo animal para um bom desempenho.

Não houve interação $(\mathrm{P}>0,05)$ entre a associação inclusão $\mathrm{x}$ aditivos para os teores de FDN. Observou-se aumento dos níveis de FDN à medida que se elevaram os níveis de inclusão do FUGM. Além disso, o mesmo ocorreu quando se adicionou os aditivos nas silagens. Entre os aditivos, observou-se pelas médias gerais que o inoculante bacteriano permitiu maiores teores deste nutriente, enquanto que o inverso ocorreu com as silagens do grupo controle

Tabela 2. Composição química da planta de milho in natura e com diferentes valores de adição de farelo úmido de glúten de milho e aditivos amostrada no momento da ensilagem.

\begin{tabular}{|c|c|c|c|c|c|}
\hline \multirow{2}{*}{ Itens (\%) } & \multirow{2}{*}{ FUGM $^{1}$} & \multirow{2}{*}{ Controle } & \multicolumn{2}{|c|}{ Aditivos } & \multirow{2}{*}{$\mathrm{CV}, \%^{7}$} \\
\hline & & & Benzoato & Inoculante & \\
\hline \multirow{4}{*}{$\mathrm{MS}^{2}$} & 0 & 24,62 & 28,62 & 21,77 & \multirow{3}{*}{4,73} \\
\hline & 15 & 29,89 & 32,61 & 31,80 & \\
\hline & 30 & 30,02 & 33,87 & 31,79 & \\
\hline & & & $\%$ da MS & & \multirow{4}{*}{4,29} \\
\hline \multirow{3}{*}{ Cinzas } & 0 & 3,34 & 4,35 & 5,92 & \\
\hline & 15 & 4,24 & 5,18 & 4,48 & \\
\hline & 30 & 4,31 & 4,70 & 4,59 & \\
\hline \multirow{3}{*}{$\mathrm{PB}^{3}$} & 0 & 9,51 & 8,37 & 10,33 & \multirow{3}{*}{14,91} \\
\hline & 15 & 10,45 & 13,38 & 13,47 & \\
\hline & 30 & 10,57 & 13,35 & 13,39 & \\
\hline \multirow{3}{*}{$\mathrm{FDN}^{4}$} & 0 & 55,25 & 56,18 & 61,23 & \multirow{3}{*}{4,89} \\
\hline & 15 & 58,90 & 57,28 & 63,85 & \\
\hline & 30 & 59,79 & 64,36 & 66,50 & \\
\hline \multirow{3}{*}{$\mathrm{FDA}^{5}$} & 0 & 28,61 & 30,36 & 33,47 & \multirow{3}{*}{7,47} \\
\hline & 15 & 26,17 & 23,75 & 25,10 & \\
\hline & 30 & 27,23 & 22,51 & 22,07 & \\
\hline \multirow{3}{*}{$\mathrm{EE}^{6}$} & 0 & 2,27 & 2,72 & 1,95 & \multirow{3}{*}{8,35} \\
\hline & 15 & 1,83 & 0,96 & 0,96 & \\
\hline & 30 & 1,91 & 2,38 & 2,12 & \\
\hline
\end{tabular}

${ }^{1} \mathrm{FUGM}$ = farelo úmido de glúten de milho; ${ }^{2} \mathrm{MS}$ = matéria seca; ${ }^{3} \mathrm{~PB}=$ proteína bruta; ${ }^{4} \mathrm{FDN}$ = fibra em detergente neutro; ${ }^{5} \mathrm{FDA}=$ fibra em detergente ácido; ${ }^{6} \mathrm{EE}=$ extrato etéreo e ${ }^{7} \mathrm{CV} \%=$ coeficiente de variação. 
Tabela 3. Teores da composição química da silagem de milho com diferentes valores de adição de farelo úmido de glúten de milho e aditivos obtida no instante da abertura do silo.

\begin{tabular}{|c|c|c|c|c|c|c|}
\hline \multirow{2}{*}{ Itens, \% } & \multirow{2}{*}{ FUGM $^{1}$} & \multirow{2}{*}{ Controle } & \multicolumn{2}{|c|}{ Aditivos } & \multirow{2}{*}{ Média } & \multirow{2}{*}{$\mathrm{CV}, \%^{7}$} \\
\hline & & & Benzoato & Inoculante & & \\
\hline \multirow{3}{*}{$\mathrm{MS}^{2}$} & 0 & $24,64 \mathrm{aA}$ & $25,17 \mathrm{aA}$ & $23,58 \mathrm{aA}$ & 24,46 & \multirow{3}{*}{4,76} \\
\hline & 15 & $39,96 \mathrm{aB}$ & $32,72 \mathrm{aB}$ & $30,59 \mathrm{aB}$ & 31,42 & \\
\hline & 30 & $28,73 \mathrm{aB}$ & $33,84 \mathrm{bB}$ & $33,12 b C$ & 31,89 & \\
\hline \multirow{6}{*}{ Cinzas } & Média & 28,11 & 30,58 & 29,10 & & \multirow{6}{*}{7,78} \\
\hline & & & $\%$ da MS & & & \\
\hline & 0 & $4,85 \mathrm{aA}$ & $5,44 \mathrm{aA}$ & $5,08 \mathrm{aA}$ & 5,12 & \\
\hline & 15 & $5,77 \mathrm{bB}$ & $6,47 \mathrm{cB}$ & $4,54 \mathrm{aA}$ & 5,59 & \\
\hline & 30 & $4,40 \mathrm{aA}$ & $4,90 \mathrm{aA}$ & $5,03 \mathrm{aA}$ & 4,77 & \\
\hline & Média & 5,00 & 5,60 & 4,88 & & \\
\hline \multirow{4}{*}{$\mathrm{PB}^{3}$} & 0 & 9,99aA & $10,13 \mathrm{aA}$ & $10,42 \mathrm{aA}$ & 10,18 & \multirow{4}{*}{10,88} \\
\hline & 15 & $8,53 \mathrm{aA}$ & $12,90 \mathrm{cB}$ & $10,71 \mathrm{bA}$ & 10,71 & \\
\hline & 30 & $10,79 \mathrm{aA}$ & $12,47 \mathrm{aB}$ & $13,27 \mathrm{aB}$ & 12,17 & \\
\hline & Média & 9,77 & 11,83 & 11,47 & & \\
\hline \multirow{4}{*}{$\mathrm{FDN}^{4}$} & 0 & 51,14 & 53,43 & 57,74 & $54,10 \mathrm{a}$ & \multirow{4}{*}{5,77} \\
\hline & 15 & 53,83 & 63,71 & 66,72 & $61,42 b$ & \\
\hline & 30 & 65,36 & 64,22 & 69,25 & $66,27 \mathrm{c}$ & \\
\hline & Média & $56,77 \mathrm{a}$ & $60,45 b$ & $64,57 \mathrm{c}$ & & \\
\hline \multirow{4}{*}{$\mathrm{FDA}^{5}$} & 0 & 17,36 & 14,44 & 16,77 & $16,19 b$ & \multirow{4}{*}{15,99} \\
\hline & 15 & 15,05 & 9,71 & 8,97 & $11,24 \mathrm{a}$ & \\
\hline & 30 & 13,01 & 12,05 & 12,03 & $12,36 \mathrm{a}$ & \\
\hline & Média & $15,14 \mathrm{~b}$ & $12,07 \mathrm{a}$ & $12,59 \mathrm{a}$ & & \\
\hline \multirow{4}{*}{$\mathrm{EE}^{6}$} & 0 & $2,16 \mathrm{aA}$ & $2,64 \mathrm{aA}$ & $2,33 \mathrm{aA}$ & 2,37 & \multirow{4}{*}{12,00} \\
\hline & 15 & $1,84 \mathrm{aA}$ & $2,30 \mathrm{aA}$ & $3,50 \mathrm{bB}$ & 2,54 & \\
\hline & 30 & $2,83 \mathrm{bB}$ & $2,21 \mathrm{aA}$ & $1,87 \mathrm{aA}$ & 2,30 & \\
\hline & Média & 2,27 & 2,38 & 2,57 & & \\
\hline
\end{tabular}

${ }^{1}$ FUGM = farelo úmido de glúten de milho; ${ }^{2} \mathrm{MS}=$ matéria seca; ${ }^{3} \mathrm{~PB}=$ proteína bruta; ${ }^{4} \mathrm{FDN}$ = fibra em detergente neutro; ${ }^{5} \mathrm{FDA}=$ fibra em detergente ácido; ${ }^{6} \mathrm{EE}=$ extrato etéreo e ${ }^{7} \mathrm{CV} \%=$ coeficiente de variação. ${ }^{8}$ Médias seguidas por letras minúsculas iguais nas linhas e maiúsculas iguais nas colunas não possuem diferença entre si segundo o teste Scott-Knott com valor de 5\% de significância.

Não houve interação $(\mathrm{P}>0,05)$ entre a associação inclusão de FUGM e os inoculantes e o benzoato para as quantidades de fibra em detergente ácido encontradas nas silagens. Observam-se pelas médias gerais maiores teores de FDA nas silagens sem aditivos, bem como sem níveis de inclusão. Por outro lado, menores níveis são encontrados em silagens tratadas com aditivos e com 15 e $30 \%$ de inclusão do coproduto.

Provavelmente o aumento nas proporções de matéria seca e a pouca diminuição destes teores em algumas silagens durante a fermentação permitiram a redução proporcional nos teores de FDA (França et al., 2015). De mesmo modo, as diminuições nos teores de PB neste período foram pouco acentuadas, diminuindo proporcionalmente os teores de FDA, visto que não houve alta degradação proteica.
De acordo com Neumann et al. (2017) a variável FDN é uma importante fonte de nutrientes para ruminantes, pois estimula a ruminação e, consequentemente, a saúde do rúmen. Ainda segundo o autor, os teores de FDA não devem ser elevados, já que esta é constituída por lignina de porção indigestível, celulose parcialmente digestível e hemicelulose, com maior digestibilidade. Neste experimento tanto o teor de FDN quanto de FDA sofreram reduções.

Em relação ao extrato etéreo não houve diferença $(\mathrm{P}>0,05)$ entre as silagens tratadas com aditivos e sem FUGM. Nas silagens incluídas de $15 \%$ do coproduto não houve diferença $(\mathrm{P}>0,05)$ entre o grupo controle e benzoato. $\mathrm{O}$ grupo com inoculante bacteriano apresentou maior teor do nutriente. Nas silagens adicionadas de $30 \%$ do 
coproduto não houve diferença $(\mathrm{P}>0,05)$ entre os grupos tratados com benzoato e inoculante, sendo o grupo controle o que apresentou o maior valor para o teor de extrato etéreo.

Segundo Santos et al. (2012) os valores de EE podem ter sido influenciados por sua característica lipossolúvel, já que avaliando diferentes tipos e tempos de ensilagem do farelo úmido de glúten de milho, este autor observou efeito da MS sobre os teores de PB devido à lixiviação ocorrida, favorecendo $\mathrm{o}$ arrastamento de compostos hidrossolúveis mais facilmente que os lipossolúveis, explicando tal dinâmica.

Conclui-se, portanto, que as inclusões de 15 ou $30 \%$ do coproduto farelo úmido de glúten de milho não apresentaram influência sobre a composição química da silagem de milho com aditivos. Dessa forma, o armazenamento da silagem com o coproduto pode ser realizada de forma a minimizar os curtos com a produção do alimento conservado sem alterar seu valor nutricional. Sugerem-se pesquisas posteriores para disponibilizar informações aos criadores e produtores sobre as melhores combinações de aditivos e subprodutos para cada tipo de produção e região (devido aos custos com transporte dos coprodutos) e assim atender à demanda nutricional dos animais de maneira econômica e sustentável.

\section{Referências bibliográficas}

Assad, L. V. F., Zervoudakis, J. T., Cabral, L. S., Hatamoto-Zervoudakis, L. K., Silva-Marques, R. P., Koscheck, J. F. W., ... \& Micheletti, M. V. 2015. Proteína degradável no rúmen e frequência de suplementação para recria de novilhos em pastejo. Semina: Ciências Agrárias, 36, 2119-2130.

Ferreira, D. F. 2011. Sisvar: a computer statistic alanalysis system. Ciência e Agrotecnologia, 35, 1039-1042.

França, A. M. S., Ferreira, I. C., Hermisdorff, I. C., Mendonça, E. P., Fernandes, E. A. \& Rossi, D. A. 2015. Dinâmica química, microbiológica e física da silagem de farelo úmido de glúten de milho. Ciência Rural, 45, 684-689.

Junior, M. C., Jobim, C. C., Osmari, M. P. \& Tres, T. T. 2017. Nutritional additives in high moisture corn silage. Revista Brasileira de Ciências Agrárias, 12, 105-111.
Marafon, F., Neumann, M., Carletto, R., Wrobel, F. L., Mendes, E. D., Spada, C.A. \& Faria, M. V. 2015. Características nutricionais e perdas no processo fermentativo de silagens de milho, colhidas em diferentes estádios reprodutivos com diferentes processamentos de grãos. Semina: Ciências Agrárias, 36, 917-93.

Moraes, R. L., Ribeiro, K. G., Pereira, O. G., Marcondes, M. I. \& Cardoso, L. L. 2017. Silagem de cana-de-açúcar tratada com inoculantes microbianos e suas misturas. Revista Brasileira de Agropecuária Sustentável, 7, 76-83.

Moreira, F. S., Oliveira, M. M. N. F., Villela, S. D. J., Barbosa, F. A., Mourthe, M. H. F. \& Diniz, D. B. 2015. Desempenho produtivo e econômico de três grupos genéticos de bovinos recriados a pasto com suplementação e terminados em confinamento. Arquivo Brasileiro de Medicina Veterinária e Zootecnia, 67, 140-148.

Neumann, M., Leão, G. F. M., Coelho, M. G., Figueira, D. N., Spada, C. A. \& Perussolo, L. F. 2017. Aspectos produtivos, nutricionais e bioeconômicos de híbridos de milho para produção de silagem. Archivos de Zootecnia, 66, 51-58.

Santos, G., Moraes, J. M. M. \& Nussio, L. G. 2017. Custo e análise de sensibilidade na produção de silagem. Revista iPecege, 3, 3948.

Santos, S. F., Gonçalves, M. F., Rios, M. P., Sousa, J. T. L., Oliveira, M. V., Miranda, M. M., ... \& Ferreira, I. C. 2012. Caracterização das Silagens de Milho com Diferentes Níveis de Inclusão de Farelo úmido de Glúten de Milho. Veterinária Notícias, 18, 119-123.

Silva, D. J. \& Queiroz, A. Z. 2006. Análise de Alimentos: Métodos químicos e biológicos. Editora UFV, Viçosa, BR.

Recebido: 9 Julho, 2018.

Aprovado: 13 Agosto, 2018

Publicado: 3 Setembro, 2018

Licenciamento: Este artigo é publicado na modalidade Acesso Aberto sob a licença Creative Commons Atribuição 4.0 (CC-BY 4.0), a qual permite uso irrestrito, distribuição, reprodução em qualquer meio, desde que o autor e a fonte sejam devidamente creditados. 